\title{
AC 2010-529: STUDENTS TAILOR A PRACTICAL WEB CONTENT MANAGEMENT SYSTEM FOR EFFECTIVE COMMUNICATION AND COORDINATION AMONG INTEGRATED PROJECT TEAMS OF INDUSTRY, GOVERNMENT, AND ACADEMIC RESEARCHERS
}

Matthew Huff, University of Idaho

Edward William, University of Idaho

Vishu Gupta, University of Idaho

Herbert Hess, University of Idaho 


\section{Students Tailor a Practical Web Content Management System for Effective Communication and Coordination Among Integrated Project Teams of Industry, Government, and Academic Researchers}

Introduction

To develop a State of Charge Indicator (SOCI), a team of industry, government, and academics was assembled. This team included entrepreneurs who run a small business in Atlanta, an industry participant in Wisconsin, a professor and two graduate students in a joint two-university cooperative teaching program in Idaho Falls, Idaho, a professor and three graduate students in Moscow, Idaho, and a government project officer in Maryland. Originally, the project consisted of just the entrepreneur and the professor in Moscow. Communication by email and telephone was easy and sufficient. Then the project grew and gained students and industry participants. As the project grew, communications soon sorely needed improvement. The document exchange became a blizzard of email attachments that were difficult to keep track of, let along verify who received and read which documents. Written meeting minutes became necessary but lagged considerably.

This paper describes a communication strategy that students developed to improve communications for such a diverse, widely scattered group. In the process, the students learned valuable lessons in communication, project management, personal style and preference in performing research work, and management and protection of intellectual property. The strategy was developed as part of three classes offered through the two universities. It became the means by which all concerned with the project kept track of its progress. It served as a means of documentation and archive, eventually being incorporated easily into theses, presentations, and reports. It emphasized the importance of protecting intellectual property in a practical and unforgettable manner.

The main campus students created a website approach to deal with the document exchange problem, initially through Google Docs ${ }^{\circledR}$. What they developed did store and distribute documents, but it did a lot more. It contained each team member's calendar, created through Google ${ }^{\circledR}$. Meeting minutes were created on line during each meeting and automatically posted in real time. (One of the graduate students learned how to do this as part of his duties as Education Chair for the National Society of Black Engineers (NSBE).) Sensitive reference documents were posted in a secure section of the website. If copyright permission was necessary, appropriate letters, citations, or URLs were posted instead of actual documents when the university had paid for access; from these posted documents granting permission, appropriate forwarding links were provided. All links to copyrighted material were password protected with access granted only to authorized, paying parties. Access to licenses for electronics design software for circuit boards, microcontrollers, battery simulation, and testing results took the form of server based licenses purchased specifically for multiple seats and multiple locations.

This attention to detail on intellectual property led to an important change of platform. As the project developed, the students determined that Google Docs® was not the best platform for copyrighted material or even for links to copyrighted material. Google ${ }^{\circ}$ claims swnership of materials posted on Google Docs ${ }^{\circledR}$. Such concerns for intellectual property rights motivated the 
teams to abandon Google Docs ${ }^{\circledR}$ in favor of WebGUI ${ }^{\mathrm{TM}}$. This paper will explain the contents of the website and how the team maintained contact even when scattered during a summer and when relocated for the fall semester as well as the intellectual property concerns.

\section{The Benefits of WebGUITM}

WebGUI $^{\mathrm{TM}}$ is the current platform that the students have found best for the communicating the information necessary for the project's success. WebGUI ${ }^{\mathrm{TM}}$ was originally built as an application framework by creator Plain Black Corporation [1] to support their customer development work, but a majority of current independent users of it utilize it as a Content Management System (CMS) with the modules with which it ships [2]. Everything in WebGUI ${ }^{\mathrm{TM}}$ is a template, which allows for customization, and keeps site content and style separate. The students adapted it for this project as the specific subset of a CMS known as a Web CMS, a class of CMS that allows "content creators to submit content without requiring technical knowledge of html or uploading of files".[3]

With WebGUI ${ }^{\mathrm{TM}}$, users can create the objects shown in Table 1. The more salient of these benefits for the student-managed Web CMS at hand are amplified in the discussion that follows.[4,5]

Table 1. Benefits of WebGUITM

\begin{tabular}{|ll|}
\hline - Forums (Flat, Nested, and Threaded & - Syndicated News (includes aggregation) \\
views) & - Events Calendars \\
- SQL Reports (Drill down and & - Articles \\
hierarchical queries) & - Search Engines \\
- Web Log (blogs) & - Web Services Front End \\
- Photo Galleries & - Matrix Comparison Systems \\
- News Listings & - In/Out Boards \\
- FAQs & - Project Management \\
- User Contributions & - Time Tracking \\
\hline
\end{tabular}

\section{Forums}

The SOCI project was funded for the expressed purpose of creating intellectual property, in this case a patentable State-of-Charge Indicator for a specific battery type. Rightly, the industry partners insisted on protection of the intellectual property. When the students began to create the Web CMS to manage the large information load, they found a host of formats, capabilities, and restrictions on ownership of information placed in certain "free" on-line CMS software. In order to own and protect the intellectual properties and document ownership WebGUI ${ }^{\mathrm{TM}}$ provided a solution for document tracking in the form of forums. The SOCI Development team increased productivity and workflow by utilizing these forums among the Industry Team in Atlanta, Remote University Team in Idaho Falls, and Local University Team in Moscow. The following example explains how this was done.

A sub-forum labeled "Documents in Progress" tracks versions of a team document. The Local University Team usually starts the document and checks it in initially as version 001. Next the Remote University team checks out the document. The Remote University Team then adds data 
to the file and saves as version 002. Finally, the Industry Team is responsible for quality control and reviews the document. Once the document is reviewed, it's checked back into the sub forum and saved as document FINAL. The WebGUI TM administrator /operator, as student on the Local University Team, monitors this process. He has authority to alert members of each team and to roll back revisions, if necessary. Hence, though information is created, shared, revised, and verified, students manage it at every step.

This ability to originate, modify, monitor, and finalize documents tamed the blizzard of documents while giving each individual and team the ability to contribute in real time. A particularly popular capability is interactive editing, where participants at different locations can simultaneously and instantly see results. Another popular feature is the automatic archiving of all versions of every document within the forum: Archiving gives everyone instant reference to the most recent version. These examples show the appropriateness of a WebGUI ${ }^{\mathrm{TM}}$ tool known as a forum for student-centered management of large quantities of this project's information.

SQL reports

The Remote University Team uses the SQL reports to drill down statistical queries of how much the site is utilized, how many failed login attempts into the site, and how much file size is uploaded and downloaded per day. This is useful information for statistical analysis of reports. In other words, each user can readily see who uses the site and in what pattern. For example, it quickly became apparent that the Local University Team and the Remote University Team used the site to communicate regularly and often, particularly as the research was ongoing. The Industry Team preferred to access documents closer to the time that such documents became final. They did more of a review than an ongoing origination and preferred to do ongoing work through email and telephone. WebGUI ${ }^{\mathrm{TM}}$ showed such interaction and did not preclude individual style or preference. Everyone gained a knowledge and appreciation for the style of others in the group, an appreciation that the WebGUI ${ }^{\mathrm{TM}}$ CMS made possible. This appreciation is an important part of learning for students who will likely be managing technical people and information upon graduation.

Web Log (blogs) and Wiki

The Local University team utilized this object to host meetings and track meeting minutes on a weekly basis. Over a period of time, thirty meetings were logged. Creating a meeting record is the strength of this feature. A scribe at one location takes the minutes as the meeting progresses. At the end of the meeting, the scribe posts these minutes with a single command. (It is possible to take minutes in real time for all to see, but we decided instead as a group to post minutes at the end of each meeting.) Minutes can be revised, but WebGUI ${ }^{\mathrm{TM}}$ keeps track of each revision and who made it. The scribe at every meeting is always a student.

The retrieval features are likewise quite powerful. Keywords can be typed into a search field and data can be recalled based on the search. The search can be global for all meetings or restricted to a subset of meeting minutes. For those who miss a meeting, they can recall any data. This helps in preparing the required monthly reports, a responsibility of the Industry Team, and for progress reviews, including those that the students write. 
Photo Galleries

Photo galleries allow posting of photographs is a variety of formats. These photographs became valuable tools for conveniently maintaining communication and reporting progress in near real time. For example, the government supervisor project officer, located in Maryland, wanted to assess progress of a sequence of experiments that the Local University Team performed. The Local University Team set up a camera and regularly and automatically posted a series of pictures and video of the lab and data collected. The Industry Team also used these photos for their periodic report later in the same month. Everyone gained confidence in the progress of the experiments and in the validity of the resulting data. The students record most of their photos with their cell phone cameras. They are the most enthusiastic users of this particular feature.

Comparison of WebGUI ${ }^{\mathrm{TM}}$ and alternatives

WebGUI ${ }^{\mathrm{TM}}$ has competitors. The students investigated several alternatives for Web CMS software and formulated a recommendation for the whole group. Their recommendation was restricted to low-cost alternatives; there are vastly more capable web CMS design suites available but beyond their budget. Their recommendation for WebGUI ${ }^{\mathrm{TM}}$ considered its cost, online support, and license features. Their results, citing appropriate details, is summarized in Table 2 and the discussion that follows.

Table 2. Comparison of Competing Products

\begin{tabular}{|c|c|c|c|c|}
\hline & OS & Cost & License & Online Collaboration \\
\hline WebGUI $^{\mathrm{TM}}$ & Web Browser & Free & Proprietary & Yes \\
\hline Google Docs ${ }^{\circledR}$ & Web Browser & Free & Proprietary & Yes \\
\hline MS Office & Windows, OSX & $\$ 149-\$ 679$ & Proprietary & No \\
\hline OpenOffice.org & Win. OSX. *nix & Free & GPL & No \\
\hline
\end{tabular}

- Google Docs ${ }^{\circledR}$ is an AJAX-based online office suite from Google®, Inc. The suite includes a word processor, a spreadsheet program, and a presentation editor. Available free and as an enterprise service. Interface to Google Calendar® and organized, shared document management are important strengths.

- Microsoft Office is an office suite of interrelated desktop applications, servers and services for the Microsoft Windows and Mac OS X operating systems. It also has calendar and document management features, though in an internal format.

- OpenOffice.org, commonly known as Open Office, is an open source software application suite available for a number of different computer operating systems. It is distributed as free software and written using its own GUI toolkit. It has calendar and document management features in an internal format.

The SOCI project team wanted a web browser interface, simple and effective communications, an ability to protect the intellectual rights of our project, low cost or perhaps a free interface, and online support for team collaboration. WebGUITM requires no local installation of software other than a web browser. Of course, web browsers are ubiquitous, making integration of new users a simple matter of sending a URL and a userid and password. The learning curve to implement the 
WebGUI ${ }^{\mathrm{TM}}$ system was as simple as navigating a typical website. Templates are available. As described above, communications became effective and organized. Adapting to individual tastes, each of the team members conveniently used the forums, blogs, newsletter update feature, and meeting minutes tracking via Wiki. For these reasons primarily, the students found WebGUI $^{\mathrm{TM}}$ most attractive.

In comparison, Google Docs ${ }^{\circledR}$ was also attractive to use for team development. It has similar features and comparable ease of operation and interface. Supervision is somewhat less timeconsuming with Google Docs $®$. However, Google's license clearly specifies that the ownership of intellectual properties is surrendered to Google upon use of Google Docs® [6,7]. For a project with intellectual property development, the Industry Team found this to be a dealbreaker. It was an important lesson in intellectual property, a lesson that most students do not encounter in school. Office-based products had their own internal formats for calendars and document management. They proved to be effective in internal document management within a team, but security can become tricky in sharing among widely separated locations.

\section{Conclusion}

Overall the WebGUI ${ }^{\mathrm{TM}}$ experience has provided helpful project management solutions. The SOCI development team utilized the revision control in the form of WebGUI ${ }^{\mathrm{TM}}$ objects. Moreover, the workflow based forum was reliable when communicating SOCI team. This feature allowed us to work on documents by checking them in and out based on SOCI team member contributions. The Wiki solution enabled us to track meeting minutes and look up keywords with ease. The WebGUI ${ }^{\mathrm{TM}}$ application is a low cost solution where content and intellectual property can be protected. WebGUI ${ }^{\mathrm{TM}}$ provided us a means of organizing and coordinating the work of widely separated teams. The students encountered issues and learned lessons in providing innovative and effective communications in a diverse industry-government-university collaborative environment. They also discovered a big problem affecting intellectual property

and recommended a reasonable course of action that the group approved. This was a valuable lesson few students encounter in their schooling.

\section{References}

[1] Plain Black Corporation. (2008, March 4). "WebGUI ${ }^{\mathrm{TM}}$ : advisories". Retrieved 8 January 2010 from WebGUI ${ }^{\mathrm{TM}}$ website: http://www.webgui.org/getwebgui/advisories/ .

[2] Plain Black Corporation. (2010, January 8). "JT Smith: Web Done Right”, Retrieved 8 January 2010 from Plain Black Corporation website http://www.plainblack.com/jt-smith

[3] Wikipedia, The Free Encyclopedia. (2010, January 8). "Content Management Systems, Retrieved 8 January 2010 from Wikipedia website: http://en.wikipedia.org/wiki/Content_management_system.

[4] Patrick. (2009, October 12). "PlebGUI: WebGUITM Meets Plack," Retrieved 8 January 2010 from patspam.com blog website: http://blog.patspam.com/2009/plebgui-webgui-meets-plack .

[5] Plain Black Corporation. (2010, January 8). "How to...". Retrieved 8 January 2010 from WebGUI ${ }^{\mathrm{TM}}$ website: http://www.webgui.org/wiki?func=byKeyword;keyword=howto

[6] Greenbaum, J. (2007, August 28). “The Content of Google Apps belongs to Google®”, Retrieved 8 January 2010 from Joshua Greenbaum blog website: http://blogs.zdnet.com/Greenbaum/?p=130 .

[7] Google Corporation. (2007, April 16). "Google® Terms of Service”, Retrieved 8 January 2010 from Google

Terms of Service website: http://www.google.com/accounts/TOS. 